\title{
From Industry Professionals to Secondary School Teachers: The Relationship between Second Career-Changing Teachers and Social Cognitive Career Theory
}

\author{
Luis M. Dos Santos \\ Woosong University, \\ 196-5 Jayang Dong, \\ Daejeon, 34514, South Korea
}

DOI: https://doi.org/10.36941/ajis-2021-o13o

\begin{abstract}
The science, technology, engineering, and mathematics (STEM) education and teaching field is facing significant human resources shortages, particularly in the subject matter of environmental sciences education. The current study collected interview and focus group data and sharing from 220 pre-service and in-service second career-changing teachers in the United States about their career decision and decisionmaking process. The results of this study indicated that the participants believe educating the next generation is their priority of joining the education and teaching profession. Many expressed that the populations of STEM teachers with professional and industry experiences are greatly needed. The outcomes of this study provided the blueprint for researchers, school leaders, policymakers and human resources planners to reform and polish their current plans for teachers training and professional development in order to solve the workforce issues in the fields of STEM education and teaching.
\end{abstract}

Keywords: human resources management, school administration, science teaching, second career changing teacher, secondary school teaching, social cognitive career theory, STEM education, teacher's shortage

\section{Introduction}

Environmental science is an interdisciplinary scientific field concerned with biology, chemistry, earth science, ecology, and geography. However, due to the human resources shortages of both Sciences, Technology, Engineering, and Mathematics (STEM) teachers and practising scientists, both fields face significant problems about qualified professionals (Dos Santos, 2019a). Although there is a reasonable amount of STEM pre-service teachers graduated from one of the Bachelor of Education programmes with internships and placements experiences, many of these graduates may fill the human resources gaps of the traditional science subject matters, such as biology, chemistry, physics, and mathematics (Reinhold et al., 2018). As environmental science and education are unique subject matter, secondary school teachers need to complete a related degree to teach this subject matter at the secondary school level.

As mentioned above, when discussing science subject matters in secondary school environments, many studies and professionals may focus on the traditional subject matters, such as 
biology, chemistry, physics, and mathematics (Daskolia et al., 2012). As environmental science teachers need to gain a particular license and registration in order to teach environmental science education, there is a need to recruit potential teachers with the relevant degree and background for this registration and license. A previous study (Dimick, 2012) suggested that due to the unbalanced social justice, environmental education and related science education should be greatly developed and reformed to meet the needs of the current students in our classroom environments.

In fact, in engineering and the practising science industry, most scientists are male professionals, where female individuals are considered minorities. Some studies indicated that female scientists might face discrimination, social stigma and social bias due to their gender as the public members tend to believe in the abilities and skills of male scientists and engineers (Shi, 2018). According to a previous study (Blatt, 2015), environmental sciences courses need to have interdisciplinary knowledge and learning materials within the curriculum and instructions. However, due to the demanding workload in teaching, many professional environmental scientists have no interests in teaching in the current school systems. Although the government agencies and university provided help and scholarships for second-career changing teachers, only a few in-service professionals decided to change their career developments and pathways (Bullough \& Knowles, 1990; Chambers, 2002).

On the other hand, both primary and secondary systems are considered as the femaledominated professions due to the non-profit status, social caring orientation, and lower-level of salary (Johnson, 2008; Martino \& Kehler, 2006; Skelton, 2003). Unlike the science industry and profession, where male professionals are the dominant staff and people, it is hard for male professionals to enter the teaching professions due to the social bias (i.e. toward the teaching profession) (Cooper \& Mackenzie Davey, 2011; Farquhar, 1998). More importantly, some studies (Booy et al., 2012; Farquhar, 1998; Griffith, 2010) indicated that the enrollment of education faculties usually has higher-level female students' enrollment. The statistics indicated that it is more likely that female individuals would like to join the education and teaching profession as their life-long development. In short, the STEM education faces both conflicts and pressures from gender and social biases (Booy et al., 2012; Moss-Racusin et al., 2018; Simon et al., 2017). Therefore, the fields of STEM education experienced significant workforce shortages due to both conflicts and biases.

\subsection{Problems of the Practice}

However, based on the social bias between the gender and expectation of education and teaching professionals, there are three conflicts in the field. First, although there are no laws and regulations to limit the university selection and major choice for both secondary school graduates and adult applicants, the general public members still believe female individuals should study liberal arts subjects. In contrast, male individuals should stay the science subject matters due to gender bias (Im et al., 2016).

Second, besides gender and social bias, the enrolments of female students in the fields of STEM are significantly lower than male students. Although teachers, parents, and counsellors encourage female students to join the STEM profession, the selection of a university major is totally up to the career decision of the individuals (Dos Santos, 2020a). In other words, the selection of non-STEM university major is controlled by the students but not the government agencies and human resources planners.

Third, education and teaching is considered a female-dominated profession, particularly in the field of primary and pre-school environments. As mentioned above, female individuals have fewer interests in the fields of STEM subject matters (Simon et al., 2017). However, male individuals do not have a strong intention to join the education and teaching profession. Based on these two factors, STEM education and teaching professions should have large human resources and workforce gaps due to gender bias and personal preference. 


\subsection{Purpose of the Study}

Based on the current problems in the fields of environmental education, there are three purposes of this study. First, school leaders have a difficult time recruiting STEM teachers, particularly environmental science teachers, in secondary school environments. In order to understand why individuals would like to join the education and teaching profession in the fields of environmental education, the researcher collected data from a group of currently enrolled pre-service teachers who are going to join the secondary teaching after graduation (i.e. with the subject matter in environmental education).

Second, the second career-changing teacher is one of the significant workforces in the fields of education and teaching. In fact, secondary school students, parents, and leaders always welcome teachers with professional and industry background and experience for joining. These teachers may bring professional practices, hands-on experiences, lab experiments, and professional expectations from people outsides the classrooms.

Third, although the government agencies and university department head always establish plans and schemes to encourage second career-changing teachers to join the teaching profession, the results and expectations are not significantly met. It is important to understand why second careerchanging teachers decide to join the teaching profession and why they want to give up their original career pathways and join the teaching profession. Switching professions and industries during midage is not an easy step for most established professionals and workers in most societies. Therefore, the understanding and sharing a group of second career-changing teachers would be meaningful to fill the gaps in this field. Based on the purposes of this study, the current study was guided by the following two research questions:

Why would second career-changing teachers (i.e. pre-service and in-service) with professional backgrounds and experiences in environmental sciences decide to join the education and teaching profession as secondary school teachers in the United States?

How would second career-changing teachers (i.e. pre-service and in-service) describe their experiences and sense-making processes for their career decision(s)?

\subsection{Theoretical Framework: Social Cognitive Career Theory}

The social cognitive career theory (Lent et al., 1994; Lent \& Brown, 1996) was employed to understand the social issues of environmental science teachers in the United States. Lent and co-workers developed the social cognitive career theory during the 1990s. The theory was developed based on the self-efficacy approach (Bandura, 1988) and the social cognitive theory (Bandura, 1986). Originally, the social cognitive career theory concerned the relationship between the academic and goals, selfefficacy, and goals for achievements of the individuals and groups and how these elements may impact the career decision. However, due to the development of the social, cultural, and financial factors and backgrounds in the changing societies, a researcher (Dos Santos, 2021) enhanced the social cognitive career theory with additional elements. Currently, the study employed the enhanced version of the social cognitive career theory for the investigation of this study, the following outlines the five elements and factors which may influence individuals' career decision, as the following,

- Interest in career development

- Personal considerations

- Financial considerations

- Academic interest

- Achievement of education and career goals

Studies (Brown \& Lent, 2017, 2019; Dos Santos \& Lo, 2018; Dos Santos, 2019c, 2020b, 2020c) argued that individuals' career decisions, motivations, and reasons might be influenced by one or more than one element under the guidelines of the social cognitive career theory. In other words, 
individuals' career decision can be strongly influenced by a single factor. However, it is not uncommon to see different elements can inter-influence each other. Therefore, for this study, the detailed investigation for second-career changing teachers would be meaningful to outline the factors and reasons behind their stories.

\section{Methodology}

A qualitative research method (Dos Santos, 2019c, 2019d; Tang \& Dos Santos, 2017) has been employed in this study. Two tools have been taken, which were the interview and focus group activities. However, due to the COVID-19 pandemic and the recommendation of the social distancing, the interview sections and focus group activities were taken via social media applications (i.e. WhatsApp) online. Although the distance-based data collection procedure was new to most participants, all participants expressed positive feedback and opinions about the procedure and progression.

\subsection{Participants and Recruitments}

In order to increase the validity of the data, the researcher employed the snowball sampling strategy (Merriam, 2009) to recruit 220 participants for the study in the United States. First of all, based on the researcher's network, the researcher successfully invited 15 participants who met the criteria of the study. Second, all the 15 participants agreed on the study and were willing to refer potential participants with a similar background after the interview session(s). Third, after several rounds of referral and interview sessions, the researcher eventually collected 220 participants' data from the interview sessions. Fourth, to increase the study's validity, the researcher invited 1o participants into a distance-based focus group activity for further sharing. 22 focus groups were conducted. The participants must meet all the following points:

- Will complete or completed an initial teacher's training programme.

- The subject matter or content area is in environmental science or a closely related subject.

- Have at least three years of environmental science-related professional working experience.

- Will teach or currently teaching at a secondary school environment as environmental science or a close related subject.

- Non-vulnerable individuals.

\subsection{Data Collection}

First, based on the researcher's network from prior experiences, the researcher invited 15 participants for the study. The researcher contacted each for this study alongside the research protocol, interview questions, focus group questions, content forms and ethical approval. Second, the researcher arranged the individual WhatsApp interview session with each. During the interview session, the researcher employed the audio-recording function. Each interview session lasted about $60-83$ minutes.

After the interview session(s), each participant should refer to at least one individual with a similar background to this study. Fortunately, each participant referred to at least two individuals with a similar background. Third, after several rounds of referral activities and interview sessions, the researcher arranged the distance-based focus group activities via WhatsApp. In order to increase the validity of the study, the researcher invited 10 participants into a distance-based focus group activity for further sharing. 22 focus groups were conducted. During the focus group activities, the researcher only worked as the facilitator for each focus group question.

The participants shared their opinions, feedback and ideas based on their own background and experiences. Each focus group activity lasted about 100-134 minutes. Although each did not know 
each other, the distance-based focus groups were focused and smooth. The voice sharing was recorded for the reporting. After the researcher transcribed the voice messages to written transcripts, the researcher sent the related materials back to each participant for member checking purposes. All 220 participants agreed on their materials with the written agreement.

\subsection{Data Analysis}

After the data collection procedure, more than 900 pages of written transcripts were created based on the interview sessions and focus group activities. First, the researcher re-read the written transcripts multiple times in order to categorise similar groups and themes for reporting. Qualitative researchers advocated that large-size data should be narrowed down to meaningful themes and subthemes. Therefore, the researcher followed the general inductive approach (GIA) (Thomas, 2006) for the data analysis procedure. Second, the researcher followed the open-coding technique to narrow down the large-size data to the first-level themes and subthemes. At this stage, 45 themes and 44 subthemes were merged.

However, it is impossible to have such large-size themes and subthemes for reporting. Therefore, as for the third step, the researcher employed the axial-coding technique to merge the first-level themes and subthemes to the second-level themes and subthemes. At this stage, the researcher categorised three themes and three subthemes for reporting.

\subsection{Human Subject Protection}

All signed document, content forms, agreements, personal contacts, audio-recording, written transcripts, computer, and related materials were locked in a password-protected box for human subject protection. Only the researcher has the rights to read the materials and information. After the study was completed, the researcher immediately deleted the soft information and destroyed the hard copies for personal privacy. Due to the privacy, each participant was provided with an anonymous for reporting (i.e. Participant \#1). As the geographic location, age, gender, university enrolment, grade, and interned schools were not important. The researcher decided to mask the information to protect the participants from potential employers.

It is worth noting that this study was supported by the Woosong University Academic Research Funding 2021. Also, this study was a part of the conference paper that the researcher presented in a conference meeting. The current version is the updated and enhanced version with new data and materials.

\section{Results and Discussions}

During each interview session and focus group activity, the participants were asked the same interview questions and focus group questions. However, the answers and feedback were not similar due to the geographic location, life experiences, lived stories, background, and experiences. Unlike some studies focusing on traditional-age students with directed experiences from secondary schools and peer influences, the career decision and decision-making process of second career-changing teachers, both pre-service and in-service, were influenced by various factors, such as life experiences, lived stories, prior background etc. Surprisingly, all 220 participants shared the same idea, "educating the next generation" as one of their purposes and hopes for this career decision (i.e. from practising to teaching). More importantly, all expressed that they will stay in the education and teaching profession as long-term career development and investment. Table 1 outlines the themes and subthemes of this study. 
Table 1: Themes and subthemes of this study

\begin{tabular}{ll}
\hline & Themes and subthemes \\
\hline 3.1. & Educating the next generation \\
3.1.1. & The needs for STEM \\
3.1.2. & The needs for professional teachers with industry experiences \\
3.2 & Personal development to the fields of education and teaching \\
3.3. & Exploring additional opportunities other than scientists \\
3.3.1. & Life-long learning as a new professional \\
\hline
\end{tabular}

\subsection{Educating the Next Generation}

...Education is the hope of our country. We need to have good and qualified teachers for our school systems and future...I am here to help...(Participant \#33)

...If we do not enter the rural schools and STEM teaching profession...who will teach our children?...we always complain...not enough teachers...not enough experienced and qualified teachers...but who can teach?...we can teach...complaint is not the solution...we need someone...to enter the teaching profession...complaints will not help us to gain teachers...(Participant \#208)

All 220 participants shared their ideas about educating the next generation as one of their most important factors for teaching in the fields of environmental science education. First, many expressed that their previous positions in the industry might earn much more resources and better career promotions. However, many decided to switch to education and teaching due to their sense of mission for the next generation, two said,

...In the industry, I may earn more than 200,ooo USD per year due to my experiences and scientific skills in environmental engineering...but I don't think it is only about money but the mission for our children and the protection of our society...I would like to use my skills to tell children that...our environment needs your appreciation...(Participant \#88)

...I am going to gain my promotion by the end of this year...if I don't quit my job...but I think our life is not only about money...I made enough money for the rest of my life already...I want to do something for the community...for our children and the country...we have to educate new scientists for the next decades...(Participant \#198)

Second, according to a previous study (Tate et al., 2015), positive experiences may encourage many encourage people's career decision in some fields, such as education. Many participants indicated that they are interested in the field of education and teaching as they received positive learning experiences during secondary school and university periods. They could see that many of the teachers and instructors in the fields of scientific subject matters do not understand how to teach and create a positive classroom environment. Therefore, they want to enter the fields of education and teaching in order to upgrade the atmosphere of the current school systems (Zeidler, 2016). Two significant sharing was marked, said,

My university instructors at the Faculty of Sciences did not understand how to teach...the monotones, the textbook only classrooms, the boring exercises or so...these teaching strategies absolutely limited the creativity and interests of potential scientists and lab technicians...it is time to change this negative practices in the labs and schools. As I have the interests to upgrade the classroom environment, why not give me a try? (Participant \#12)

The current science classrooms are very boring. Many teachers and professors only know how to do lab experiments and reports...But we need to have interactive classroom environments to increase the overall performance and interests of our learners and students...lab experiments should be given to graduate students but not high school students...I want to change this practice...(Participant \#57) 


\subsection{The Needs for STEM}

With the reflection of a previous study (Hutchison, 2012), all 220 participants indicated that both industry and teaching areas do not have enough quality scientists and teachers in the fields of environmental sciences, environmental engineering, and environmental education. Although switching career between the areas and fields may solve the immediate and short-term human resources shortages, the long-term solutions would be positive training and recruitment for the potential newcomers. As one said,

We need to have new students and new scientists in our environmental sciences fields...just like me, changing direction from practice to teaching does not change the number of workforces...I am here to train up additional scientists from high school to university...so several years later... We will have new and fresh scientists in the environmental science labs...(Participant \#1)

\subsection{The Needs for Professional Teachers with Industry Experiences}

Many teachers in the K-12 systems do not have professional and industry experiences, as many joined the education and teaching profession right after university graduation. The lack of professional experience in the subject matters happens in the STEM classrooms and other liberal arts and social sciences classrooms. In other words, K-12 teachers usually do not have the hands-on experiences and practices of what they are teaching in classroom environments. As one said,

My high school and university instructors in environmental sciences did not even work in the professional labs before they joined teaching...so some technical terms and procedures...they do not understand...but I think schools should have a balance between professional teachers and classroombased teachers...instead of thinking about how to encourage lab technicians to join, I join it first...(Participant \#119)

In conclusion, based on the social cognitive career theory (Dos Santos, 2021), personal consideration took a significant role in career decisions and motivations. It is confirmed that most do not believe financial consideration of the teaching profession (i.e. lower salary than their industry positions) could influence their career decisions. Rather, all advocated that the next generations and the country's future were their key consideration, which matched their personal desire of their career goals and motivations.

\subsection{Personal Development to the Fields of Education and Teaching}

Many participants expressed interest in transferring the professional and industry procedures, experiences, experiments, and practices beyond the textbook materials to classroom students and their co-workers. Many indicated that although the textbook materials shared the steps and procedures of the lab experiments, these procedures are not upgraded and updated in contemporary lab environments. In other words, no lab technicians would use these procedures anymore as the developments of the scientific areas changed overnight. Therefore, they want to bring new stimuli to their next generation for creative thinking and updated knowledge, one said,

Many scientists believe that water is the essential item and element for all life matters in the universal system...I learnt this from elementary school...but who can prove this is the fact or truth?... who has the experiences...to interact with aliens? Life matters on Mars...do they have the same physical structures as life matters on Earth? We have to import some new and updated knowledge to our children...(Participant \#47)

In short, based on the current findings and results, many believed that the future of the next 
generation and the education quality of the school systems take the important roles and positions of their second career switching decision to education and teaching. With the echo from a previous study (Galosy \& Gillespie, 2013), personal development and the desire to help newly qualified teachers in the field of STEM teaching always encouraged their career decisions and motivations (i.e. for joining the teaching profession). It is important to note that many believe resources and financial incomes do not change their decision but the mission of serving the society and community. Therefore, they have established a sense of belonging to their country, community, and people as people (Pesonen et al., 2021).

\subsection{Exploring Additional Opportunities Other Than Scientists}

When the researcher asked about the concerns and challenges of switching career pathways, more than 200 participants indicated no room for worries (Smith \& White, 2019). First of all, a large group of participants indicated that experienced scientists and professionals in the field of STEM could reenter the industry without any problems. Due to their experiences and skills, all indicated that both STEM teaching and industry are thirsty for professionals. Many joined the STEM as they want to explore more ways for STEM professions, including STEM teaching. One said,

...STEM industry and the STEM teaching...are different...but similar...in my organisation and lab...I have to train up the junior workers and newcomers...in high school...I am going to train up the teenagers...I want to gain some new ideas how to train people...young adults or teenagers...I can learn new ideas, and I can learn how to train people in school...(Participant \#178)

With a reflection of a recent study (Smith \& White, 2019), experienced scientists and STEM professionals always need to provide mentorship to novice scientists and trainees in the labs or organisations. Many believed that the switching (i.e. from the industry to secondary school) does not highly influence their roles and expectations. However, the current switch increased their career opportunities as they learned new ideas and skills at the secondary school level(s) (Kendricks et al., 2019).

\subsubsection{Life-Long Learning as a New Professional}

Besides the career opportunities and new learning models, nearly 200 participants expressed their interests of gaining additional registration or license (i.e. the secondary school teacher's registration in their state). Before the data collection procedure, all hold professional license and registration in their scientific industry. The researcher captured that many would like to gain the teacher's registration and license for additional career opportunities and desires. Many indicated that the secondary school teacher's registration made them skilled workers in multiple industries and professions. Two said,

...it is great for experienced scientists to teach undergraduate and master graduates in our labs...but it is great to have the chances to teach high school students...at least I can see how I can improve my mentorship with all students...different age...(Participant \#133)

...perhaps in the future, if I don't want to train up young adults...or if I quit my lab...I can teach in some rural schools and communities...I can see the super vacancies in high schools and middle schools...I can become a multiple profession...in lab and in school...(Participant \#211)

In conclusion, based on the social cognitive career theory (Dos Santos, 2021), the interests in career development influenced individuals' career decision and motivations as many of them want to gain additional skills and registration as scientists and secondary school teachers in the field of STEM. Many indicated that they have long-term experiences in offering mentorship to undergraduate 
and master's graduates in their labs. The current secondary school teaching opportunities may increase and enhance their mentoring skills for teenagers. The multiple skills and registrations (i.e. professional registration and teacher's license) will increase their opportunities and skills in their field and future career development.

\section{Limitations and Future Research Directions}

Each study has its limitations. The researcher concluded three limitations with potential future research directions for this study. First, although the STEM teaching profession faces the significant teacher shortage and human resource issues, other fields, such as foreign language and business education, face significant workforce gaps. Therefore, future researchers may expand the directions and populations from STEM professionals to teachers with a liberal arts background to create a holistic picture in the current educational system.

Second, many STEM subject matters in the current school systems face significant shortages of qualified teachers. The voiced from traditional Bachelor of Education students, postgraduate certificate in education students, and master of art in teaching students and related graduates are greatly welcomed. Future research studies should cover the workforce problems in other STEM subject matters, such as biology, chemistry, and physics, to better picture the current human resources problems.

Third, the current study only covered workforce problems in the United States. Other countries with a similar background and human resources shortages should face a similar background and problem. Therefore, future research studies should collect data from participants in different parts of the worlds in order to establish the holistic performance of the current human resources shortages (Dos Santos, 2019b).

\section{Implications and Conclusion}

The completion of this study provided two significant insights into the human resources shortages in the fields of science education. First, although many human resources planners, university leaders, policymakers, and researchers always encourage the government to provide additional funding and scholarships for scientific training and projects, not much of this funding has contributed to upgrading the K-12 science teachers' professional development. Currently, science teachers' salary and incomes are below average compared to lab technicians and scientists. Therefore, the appropriate personnel should reform the current school systems and the salary scales to encourage additional teachers and second career-changing teachers to the fields.

Second, teachers and professors wrote many of the current textbook materials without any professional and industry experiences. Therefore, there is a need to balance and coordinate between textbook materials and professional practices in the K-12 and university classroom environments. Otherwise, school graduates would only gain textbook-oriented knowledge and outdated practices from the classroom environments, which cannot be applied to the lab and professional environments in the future.

\section{Acknowledgement:}

1) This study was supported by Woosong University Academic Research Funding 2021.

2) This study was the updated and enhanced version of a study from the researcher's conference presentation. The current study contained additional information and materials.

\section{References}

Bandura, A. (1986). Social foundations of thought and action: A social cognitive theory. Prentice-Hall. Bandura, A. (1988). Self-efficacy conception of anxiety. Anxiety Research, 1, 77-98. 
Blatt, E. (2015). An investigation of the goals for an environmental science course: Teacher and student perspectives. Environmental Education Research, 21(5), 710-733. https://doi.org/10.1080/13504622.2014.918935

Booy, C., Jansen, N., Joukes, G., \& Van Schaik, E. (2012). Trend analysis gender in higher STEM Education. National Expert Organisation Girls/Women and Science/Technology.

Brown, S., \& Lent, R. (2017). Social cognitive career theory in a diverse world. Journal of Career Assessment, 25(1), 173-18o. https://doi.org/10.1177/106907271666oo61

Brown, S., \& Lent, R. (2019). Social cognitive career theory at 25: Progress in studying the domain satisfaction and career self-management models. Journal of Career Assessment, 27(4), 563-578. https://doi.org/10.1177/1069072719852736

Bullough, R. V., \& Knowles, J. G. (1990). Becoming a teacher: struggles of a second-career beginning teacher. International Journal of Qualitative Studies in Education, 3(2), $101-112$. https://doi.org/10.1080/0951839900030201

Chambers, D. (2002). The real world and the classroom: Second-career teachers. The Clearing House: A Journal of Educational Strategies, Issues and Ideas, 75(4), 212-217. https://doi.org/10.1080/o0098650209604935

Cooper, H., \& Mackenzie Davey, K. (2011). Teaching for life? Midlife narratives from female classroom teachers who considered leaving the profession. British Journal of Guidance \& Counselling, 39(1), 83-102. https://doi.org/10.1080/03069885.2010.531386

Daskolia, M., Dimos, A., \& Kampylis, P. (2012). Secondary teachers' conceptions of creative thinking within the context of environmental education. International Journal of Environmental and Science Education, 7(2), 269-290.

Dimick, A. (2012). Student empowerment in an environmental science classroom: Toward a framework for social justice science education. Science Education, 96(6), 990-1012. https://doi.org/10.1002/sce.21035

Dos Santos, L. M., \& Lo, H. F. (2018). The development of doctoral degree curriculum in England: Perspectives from professional doctoral degree graduates. International Journal of Education Policy and Leadership, 13(6). https://doi.org/10.22230/ijepl.2018v13n6a781

Dos Santos, L. M. (2018). Career decision of recent first-generation postsecondary graduates at a metropolitan region in Canada: A social cognitive career theory approach. Alberta Journal of Educational Research, 64(2), 141-152.

Dos Santos, L. M. (2019a). Engineering education as a second career: The experience of female practising engineers. Global Journal of Engineering Education, 21(3), 202-207.

Dos Santos, L. M. (2019b). Investigating employment and career decision of health sciences teachers in the rural school districts and communities: A social cognitive career approach. International Journal of Education and Practice, 7(3), 294-309. https://doi.org/10.18488/journal.61.2019.73.294.309

Dos Santos, L. M. (2019c). Recruitment and retention of international school teachers in remote archipelagic countries: The Fiji experience. Education Sciences, 9(2), 132. https://doi.org/10.3390/educscigo20132

Dos Santos, L. M. (2019d). Experiences and expectations of international students at historically black colleges and universities: An interpretative phenomenological analysis. Education Sciences, 9(3), 189. https://doi.org/10.3390/educscigo30189

Dos Santos, L. M. (2020a). Becoming a pre-school and elementary school educator: How do male teachers describe their career decision and career development from the perspective of the social cognitive career approach and human resource management. Journal of Education and E-Learning Research, 7(2), $159-166$. https://doi.org/10.20448/journal.509.2020.72.159.166

Dos Santos, L. M. (2020b). How does COVID-19 pandemic influence the sense of belonging and decision-making process of nursing students: The study of nursing students' experiences. International Journal of Environmental Research and Public Health, 17(15), 5603. https://doi.org/10.339o/ijerph17155603

Dos Santos, L. M. (2020c). I want to become a registered nurse as a non-traditional, returning, evening, and adult student in a community college: A study of career-changing nursing students. International Journal of Environmental Research and Public Health, 17(16), 5652. https://doi.org/10.339o/ijerph17165652

Dos Santos, L. M. (2021). Developing bilingualism in nursing students: Learning foreign languages beyond the nursing curriculum. Healthcare, 9(3), 326. https://doi.org/10.3390/healthcare9030326

Farquhar, S. (1998). Teaching: A women-only profession? New Zealand Annual Review of Education, 7(1), 169-180.

Galosy, J. A., \& Gillespie, N. M. (2013). Community, inquiry, leadership: Exploring early career opportunities that support STEM teacher growth and sustainability. The Clearing House: A Journal of Educational Strategies, Issues and Ideas, 86(6), 207-215. https://doi.org/10.1080/ooo98655.2013.826485

Griffith, A. (2010). Persistence of women and minorities in STEM field majors: Is it the school that matters? Economics of Education Review, 29(6), 911-922. https://doi.org/10.1016/j.econedurev.2010.06.010 
Hutchison, L. F. (2012). Addressing the STEM teacher shortage in American schools: Ways to recruit and retain effective STEM teachers. Action in Teacher Education, 34(5-6), 541-550. https://doi.org/10.1080/01626620.2012.729483

Im, S., Yoon, H.-G., \& Cha, J. (2016). Pre-service Science Teacher Education System in South Korea: Prospects and Challenges. EURASIA Journal of Mathematics, Science and Technology Education, 12(7), 1863-1880. https://doi.org/10.12973/eurasia.2016.1533a

Johnson, S. (2008). The status of male teachers in public education today. Education Policy Brief, 6(4), 1-11.

Kendricks, K., Arment, A., Nedunuri, K. V., \& Lowell, C. (2019). Aligning best practices in student success and career preparedness: An exploratory study to establish pathways to STEM careers for undergraduate minority students. Journal of Research in Technical Careers, 3(1), 27. https://doi.org/10.9741/2578-2118.1034

Lent, R. W., \& Brown, S. D. (1996). Social cognitive approach to career development: An overview. The Career Development Quarterly, 44(4), 310-321. https://doi.org/10.1002/j.2161-0045.1996.tboo448.x

Lent, R. W., Brown, S. D., \& Hackett, G. (1994). Toward a unifying social cognitive theory of career and academic interest, choice, and performance. Journal of Vocational Behavior, 45(1), 79-122. https://doi.org/10.1006/jvbe.1994.1027

Martino, J. (2008). Male Teachers as Role Models: Addressing Issues of Masculinity, Pedagogy and the ReMasculinization of Schooling. Curriculum Inquiry, 38(2), 189-223. https://doi.org/10.1111/j.1467873X.2007.00405.X

Martino, W., \& Kehler, M. (2006). Male Teachers and the "Boy Problem": An issue of recuperative masculinity politics. McGill Journal of Education, 41(2), 113-132.

Merriam, S. B. (2009). Qualitative research: A guide to design and implementation. Jossey Bass.

Moss-Racusin, C. A., Sanzari, C., Caluori, N., \& Rabasco, H. (2018). Gender bias produces gender gaps in STEM engagement. Sex Roles, 79(11-12), 651-670. https://doi.org/10.1007/s11199-018-0902-z

Pesonen, H. V., Rytivaara, A., Palmu, I., \& Wallin, A. (2021). Teachers' stories on sense of belonging in co-teaching relationship. Scandinavian Journal of Educational Research, 65(3), 425-436. https://doi.org/10.1080/00313831.2019.1705902

Reinhold, S., Holzberger, D., \& Seidel, T. (2018). Encouraging a career in science: a research review of secondary schools' effects on students' STEM orientation. Studies in Science Education, 54(1), $69-103$. https://doi.org/10.1080/03057267.2018.1442900

Shi, Y. (2018). The puzzle of missing female engineers: Academic preparation, ability beliefs, and preferences. Economics of Education Review, 64(1), 129-143. https://doi.org/10.1016/j.econedurev.2018.04.005

Simon, R. M., Wagner, A., \& Killion, B. (2017). Gender and choosing a STEM major in college: Femininity, masculinity, chilly climate, and occupational values. Journal of Research in Science Teaching, 54(3), 299323. https://doi.org/10.1002/tea.21345

Skelton, C. (2003). Male Primary Teachers and Perceptions of Masculinity. Educational Review, 55(2), $195-209$. https://doi.org/10.1080/0013191032000072227

Smith, E., \& White, P. (2019). Where do all the STEM graduates go? Higher education, the labour market and career trajectories in the UK. Journal of Science Education and Technology, 28(1), 26-40. https://doi.org/10.1007/s10956-018-9741-5

Tang, K. H., \& Dos Santos, L. M. (2017). A brief discussion and application of interpretative phenomenological analysis in the field of health science and public health. International Journal of Learning and Development, 7(3), 123-132. https://doi.org/10.5296/ijld.v7i3.11494

Tate, K. A., Caperton, W., Kaiser, D., Pruitt, N. T., White, H., \& Hall, E. (2015). An exploration of first-generation college students' career development beliefs and experiences. Journal of Career Development, 42(4), 294310. https://doi.org/10.1177/o894845314565025

Thomas, D. R. (2006). A general inductive approach for analysing qualitative evaluation data. American Journal of Evaluation, 27(2), 237-246. https://doi.org/10.1177/1098214005283748

Zeidler, D. L. (2016). STEM education: A deficit framework for the twenty first century? A sociocultural socioscientific response. Cultural Studies of Science Education, 11(1), 11-26. https://doi.org/10.1007/s11422014-9578-z 